\title{
Galapagos land iguanas as ecosystem engineers
}

\author{
Washington Tapia $^{1,2}$, James P Gibbs ${ }^{\text {Corresp. } 2,3}$ \\ 1 Science Faculty, University of Malaga, Malaga, Spain \\ 2 \\ 2 Galapagos Conservancy, Fairfax, Virginia, United States of America \\ 3 Environmental Biology, State University of New York College of Environmental Science and Forestry, Syracuse, New York, United States of America \\ Corresponding Author: James P Gibbs \\ Email address: jpgibbs@esf.edu
}

Background. Declines of large-bodied herbivorous reptiles are well documented, but the consequences for ecosystem function are not. Understanding how large-bodied herbivorous reptiles engineer ecosystems is relevant given the current interest in restoration of tropical islands where extinction rates are disproportionately high and reptiles are prominent as herbivores.

Methods. In this study, we measured the ecosystem-level outcomes of long-term quasi-experiment represented by two adjacent islands within the Galapagos Archipelago, one with and the other without land iguanas (Conolophus subcristatus), large-bodied herbivores known to feed on many plant species. We characterized plant communities on each island by developing high-resolution $\left(<1 \mathrm{~cm}^{2}\right)$ aerial imagery and delineating extent of plant associations and counting individual plants on each.

Results. In the presence of iguanas there was $208 \%$ less woody plant cover, $52 \%$ more area with seasonal grasses, and $258 \%$ less cactus. Cacti had a more clumped distribution where iguanas were absent than where iguanas were present.

Discussion. This study provided strong evidence that large-bodied, herbivorous reptiles can substantially engineer the structure of terrestrial plant communities; therefore, restoration of largebodied reptilian herbivores, such as land iguanas and giant tortoises, should be regarded as an important component of overall ecosystem restoration, especially for tropical islands from which they have been extirpated. 


\title{
1 Galapagos land iguanas as ecosystem engineers
}

2

3

4

5

6

\author{
Washington Tapia ${ }^{1,2}$ and James P. Gibbs ${ }^{1,3}$ \\ ${ }^{1}$ Galapagos Conservancy, Fairfax, VA, USA \\ 2University of Malaga, Science Faculty, Malaga, Spain \\ ${ }^{3}$ Department of Environmental Biology, State University of New York College of Environmental \\ Science and Forestry, Syracuse, NY, USA
}

Corresponding Author:

James P. Gibbs, 1 Forestry Drive, SUNY-ESF, Syracuse, New York, USA

Email address: jpgibbs@esf.edu

\begin{abstract}
Background. Declines of large-bodied herbivorous reptiles are well documented, whereas consequences for ecosystem function are not. Understanding how large-bodied herbivorous reptiles engineer ecosystems is relevant given interest in restoration of tropical islands where extinction rates are disproportionately high and reptiles are prominent as herbivores.

Methods. In this study, we measured the ecosystem-level outcomes of long-term quasiexperiment represented by two adjacent islands within the Galapagos Archipelago, one with and the other without land iguanas (Conolophus subcristatus), large-bodied herbivores known to feed on many plants. We characterized vegetation on each island by developing high-resolution $\left(<1 \mathrm{~cm}^{2}\right)$ aerial imagery and delineating extent of plant associations and counting individual plants on each.
\end{abstract}

Results. In the presence of iguanas there was $208 \%$ less woody plant cover, $52 \%$ more area with seasonal grasses, and $258 \%$ less cactus. Cacti had a more clumped distribution where iguanas were absent than where iguanas were present.

Discussion. This study provides evidence that large-bodied, herbivorous reptiles can substantially engineer the structure of terrestrial plant communities; therefore, restoration of large-bodied reptilian herbivores, such as land iguanas and giant tortoises, should be regarded as an important component of overall ecosystem restoration, especially for tropical islands from which many have been extirpated.

\section{Introduction}

Reptiles are prominent as herbivores in tropical island ecosystems and declines in their populations on islands have been particularly severe (Gibbons et al., 2000). Reptiles are thought to "engineer" island ecosystems through herbivory, seed dispersal and nutrient cycling ( Cooper \& Vitt 2002, Falcón \& Hansen, 2018, Valido \& Olesen 2019) but the consequences of reptile declines for island ecosystems are not well known (Malhi et al., 2016, Perez-Mendez et al. 2018). The most definitive means of testing potential ecosystem-level effects of large-bodied reptiles is experimental manipulations of population numbers usually not possible because manipulation of entire landscapes is not feasible (Debinski \& Holt, 2000). Quasi-experiments (Shadish et al. 2002) do exist that have many of the qualities of designed, controlled experiments and take the form of ecosystem contrasts between adjacent islands with and without herbivores (e.g., Ali 2004), providing an opportunity to assess causal processes (Beatty, Cox, \& Kuzee, 2018).

In this study, we identified a fortuitous quasi-experimental situation represented by two adjacent islands within the Galapagos Archipelago, one with and the other without land iguanas 
50

51

52

53

54

55

56

57

58

59

60

61

62

63

64

65

66

67

68

69

70

71

72

73

74

75

76

77

78

79

80

81

82

83

84

85

86

87

88

89

90

91

92

93

94

95

96

97

98

99

(Conolophus subcristatus, Fig. 1). This species along with two other species of Galapagos land iguanas (C. marthae and C. pallidus) and giant tortoises (Chelonoidis spp.) once dominated as the only large-bodied herbivores present in the Galapagos Islands (Fabiani et al., 2011; Tzika et al., 2008). Today, all three species of land iguanas in Galapagos are listed as vulnerable or critically endangered due to past population collapses from predation by invasive predators, mainly dogs and humans, and habitat disruption by invasive herbivores, mainly goats (Kumar et al. 2020).

Land iguanas are postulated to be ecosystem engineers for several reasons. They disperse seeds over large distances (Traveset et al., 2016) and also feed on many plant species (Costantini et al., 2005). These include grasses and herbaceous plants, as well as leaves and floral parts of woody plants, potentially affecting recruitment of woody plants and thereby mediating woody plant-grass interactions in the savannah-type ecosystems where land iguanas occur. Opuntia cactus is another important food source for land iguanas. In consuming fallen cactus pads and fruits, land iguanas may diminish asexual (vegetative) reproduction while enhancing sexual reproduction via seed dispersal away from adult plants where bird predation on seeds is intense (Heleno et al., 2011; Nogales et al., 2017). The cacti are, in turn, a keystone resource for much of the terrestrial vertebrate animal community (Grant \& Grant, 1981).

To examine the ecosystem-scale impacts of land iguanas, we contrasted plant community composition on the two islands, which were similarly sized, immediately adjacent and comparable in most ways except for herbivore presence thereby largely controlling for factors potentially structuring plant communities unrelated to reptile herbivory. We characterized plant communities on each island by developing high-resolution $\left(<1 \mathrm{~cm}^{2}\right)$ aerial imagery and delineating extent of plant associations on each. Our study provided an opportunity to ask questions about the role of reptilian herbivores on structuring the plant communities of islands, including impacts on keystone plants, as well as to explore the ramifications of restoring reptile populations on islands to promote ecosystem recovery (Hansen et al., 2010).

\section{Materials \& Methods}

The Galapagos Islands are a volcanic archipelago straddling the equator $1000 \mathrm{~km}$ west of continental Ecuador (Fig. 1a). Climate is unusually dry and cold for their equatorial position with average annual rainfall around $500 \mathrm{~mm}$ in coastal areas and temperatures varying annually between only 15 to $21 \mathrm{C}$. This study focused on the Plaza Islands, which are typical of the 128 small islands that comprise the archipelago (Peck \& Kukalová-Peck, 1990). South Plaza (0034'56.3"S,9009'57.0"W, 12 ha) and North Plaza (0034'36"S,9009'32"W, 9 ha) are situated side-by-side $200 \mathrm{~m}$ apart and $500 \mathrm{~m}$ off the eastern coast of Santa Cruz Island (Fig. 1a,c). Each island has scattered expanses of soil on their uplands derived from the basaltic lava flows that comprise them. . Plant communities are composed of shrubs, trees and tree-like cacti, and scattered seasonal grasses, herbs and sedges. Among 36 species of plants recorded on the Plaza islands, the following are the most widespread and form the basis for primary plant community associations: grasses and sedges - Aristida subspicata (Poaceae), Bouteloua disticha (Poaceae), Cyperus anderssonii (Cyperaceae), Panicum laxum (Poaceae), Sporobolus pyramidatus (Poaceae); woody plants - Acacia rorudiana (Mimosaceae), Bursera graveolens (Burseraceae), Maytenus octogona (Celastraceae), Parkinsonia aculeata (Caesalpinaceae), and Scutia spicata (Rhamnaceae); succulents - Sesuvium edmonstonei (Aizoaceae), and cactus - Opuntia echios (Cactaceae).

The vertebrate fauna of the two islands differs primarily in terms of the presence and absence of land iguanas. Densities of land iguanas on South Plaza Island have been reported at > 55 per hectare (Snell \& Christian, 1985) whereas land iguanas have never been reported from North Plaza Island. Tourism is permitted on South Plaza Island and not on North Plaza Island but tourists are restricted to particular, narrow paths that generate little aggregate impact

Peer) reviewing PDF | (2021:05:61822:2:0:NEW 23 Nov 2021) 
100

101

102

103

104

105

106

107

108

109

110

111

112

113

114

115

116

117

118

119

120

121

122

123

124

125

126

127

128

129

130

131

132

133

134

135

136

137

138

139

140

141

142

143

144

145

146

147

148

149

on the island's habitat ( $<1 \%$ trail-impacted). The elevation of the islands is similar but topography of South Plaza is more gradually sloping to its north shore whereas North Plaza is largely surrounded by cliffs that may permit less access to marine mammals (sea lions, Zalophus wollebaeki) to enter the island for resting. A final biotic difference known to occur between the islands other than presence / absence of land iguanas was the former existence of a small cohort of goats (five individuals were removed in 1961, Campbell \& Donlan 2005) and presence of house mice ca. 1982 to 2012 (now eradicated), both on South Plaza Island. During their period of occupation mice are hypothesized to have impacted cactus via burrowing into roots which in turn may have made cacti more vulnerable to toppling during wet periods (Snell et al. 1994) with iguanas simultaneously consuming cactus that may have fallen.

To obtain detailed data on vegetation for each island, we secured ultrahigh-resolution imagery of vegetation using an electric-powered, hand-launched octocopter of our own design (see Fondriest, 2014). Pre-planned fight paths were uploaded and autonomously executed by the aircraft at $50 \mathrm{~m}$ flight altitude over 8 hours on May 12, 2012. The optical payload consisted of a commercial, off-the-shelf Canon S110 10 megapixel digital single-lens reflex camera suspended on a custom-designed, passive gimbal. Two images were captured per second with auto adjustment for exposure during each flight producing images with approximately $1 \mathrm{~cm}^{2}$ ground resolution. Post-processing of the imagery was accomplished with Agisoft Photoscan image stitching software (Agisoft LLC, St. Petersburg, Russia) using the Geospatial Data Abstraction Library for geo encoding, warping and tiling supported with Python 3.4 and Imagemagick software (ImageMagick Development Team, 2021). Fieldwork was performed under research permit PC-82-14 granted by the Galapagos National Park Directorate.

Once the ultrahigh resolution imagery was mosaicked, we quantified vegetation on each island by overlaying a 5x5 m grid and estimating visually, based on expert knowledge of ground conditions, the proportion of each grid cell made up by the following: Grasses: seasonal grasses and herbaceous vegetation that otherwise were underlain by soil; Succulents: succulent plants that form dense monospecific mats over parts of these islands, Woody plants: shrubs or small trees; Cactus: the arboreal cactus present; and Marine mammal impact areas: areas with compacted marine mammal feces with sparse plant growth distinguished by the bright white appearance resulting from accumulated feces being compacted and polished by mammals "hauling" over them repeatedly. We additionally counted the number of individual cactus plants occurring in each $5 \times 5 \mathrm{~m}$ grid cell. To assess differences in overall plant community compositions between islands, we performed nonmetric multidimensional scaling using BrayCurtis dissimilarities between islands (nMDS(); vegan package) in R (R Core Team, 2017). To measure impacts of iguanas on cactus distribution, we assumed a Poisson process and indexed the spatial dispersion of cacti in the presence and absence of iguanas using the ratio of the variance-to-mean count of cacti (Clapham, 1936).

\section{Results}

We classified extent of vegetation on 1,148, 5x5 m grid cells on North Plaza Island (iguanas absent) and 1,777 grid cells on South Plaza island (iguanas present) (Fig. 1c). Vegetation composition differed substantially between islands: in the presence of iguanas there was $208 \%$ less woody plant cover and $52 \%$ more area with seasonal grasses (Fig. 2). Notably there was $258 \%$ less cactus in the presence of iguanas (Fig. 2). Correlation of woody cover extent in each grid cell versus its extent in the eight neighboring grid cells (Fig. 2) suggested that cells with woody plant cover tended to be surrounded by more cells with a higher proportion of woody plants, on average, in the presence of iguanas than in their absence. The dispersion parameter for cactus was considerably lower (2.94) where iguanas were present, indicating a less clumped dispersion of cactus, than where iguanas were absent (4.05). Multivariate assessment of plant communities on each island (Fig. 3) revealed that areas dominated by grasses only and marine

Peer) reviewing PDF | (2021:05:61822:2:0:NEW 23 Nov 2021) 
150

151

152

153

154

155

156

157

158

159

160

161

162

163

164

165

166

167

168

169

170

171

172

173

174

175

176

177

178

179

180

181

182

183

184

185

186

187

188

189

190

191

192

193

194

195

196

197

198

199

mammal impacts only were unique to the island with iguanas present whereas areas with $100 \%$ woody plant cover were unique to the island lacking iguanas. Large extents of both islands shared plant community associations characterized as combinations of woody plants and grasses as well as grasses and succulents, with some further overlap in areas dominated by marine mammal impacts and succulents.

\section{Discussion}

This study provides evidence that large-bodied, herbivorous reptiles can substantially engineer the structure of terrestrial plant communities. Not only was woody vegetation far less extensive on the island with land iguanas, the spatial pattern of woody vegetation also differed insofar as it tended to be surrounded by more woody vegetation in the presence of iguanas than in their absence. Land iguana impacts on cactus - a keystone species for the entire vertebrate community -- were also substantial, reducing cactus abundance and altering spatial distribution of cactus.

We suspect the dramatic contrasts in vegetation between islands were due primarily to herbivory by iguanas. Land iguanas consume fruits, flowers, leaves and shoots of woody plants, including those of species that dominated on the Plazas Islands (Christian et al. 1984; Traveset et al. 2016). Targeted herbivory on vulnerable parts (leaves, shots) of regenerating woody plants is likely the primary mechanism by which land iguanas reduced woody plant cover because these large-bodied land iguanas, due to their weight (up to $10 \mathrm{~kg}$ ), cannot be supported on peripheral branches of shrubs and trees and cannot consume their crown foliage. As for cactus, land iguanas primarily consume fallen cladodes, but also consume fallen fruits. Land iguana consumption of fallen cladodes near adults eliminates asexual reproduction in cacti that generates clustered distribution of cacti, whereas iguanas dispersing seeds away from adult cacti and the intense seed predation that occurs there by birds (Nogales et al., 2017), thereby promoting sexual reproduction in cactus and wider dispersion of cactus individuals, a pattern we observed.

Land iguana herbivory may well have a cascading effect on the biotic community of small oceanic islands, by influencing other terrestrial vertebrates through changes in habitat structure and composition. One important interaction likely resulting from iguana herbivory with impacts on many other species on the Plazas Islands involves marine mammals. Sea lions cannot navigate through woody vegetation when seeking basking sites, and occupy more sparsely vegetated areas facilitated by iguanas. Sea lions deposit prolific amounts of guano with attendant changes in the soil chemistry (Fariña et al., 2003). Notably the extent of marine mammal impacts was greater on the iguana-occupied island (Fig. 1c). Further studies contrasting the animal communities (birds, other lizards, invertebrates) would inform how iguana-triggered changes in plant communities trigger cascading into the larger biotic community on these islands.

A primary limitation of our study is that it represents a pseudo-replicated design with one replicate within each treatment. Unfortunately given the widespread extinctions of island forms of large-bodied reptilian herbivores elsewhere in Galapagos and around the world (Simberloff, 1976; Slavenko et al., 2016; Foufopoulos \& Ives, 2017), there are few opportunities to increase the replicate number (number of islands) to strengthen inference. The historical occurrences of a tiny population of goats (1960's) as well as house mice (1-2 decades previously) on South Plaza Island may have impacted vegetation at the time of their tenure (Campbell, Carrión, \& Sevilla, 2013; Snell \& Christian, 1985) but are unlikely to account for the striking differences in plant communities evident today. A significant structuring agent, however, may be marine mammals. South Plaza presents a more gradual northern slope such that it is more heavily accessed by sea lions for resting. Land iguanas may facilitate sea lion use of the island's uplands by reducing woody plant cover, with sea lions then via trampling and altering soil

Peer] reviewing PDF | (2021:05:61822:2:0:NEW 23 Nov 2021) 
200

201

202

203

204

205

206

207

208

209

210

211

212

213

214

215

216

217

218

219

220

221

222

223

224

225

226

227

228

229

230

231

232

233

234

235

236

237

238

239

240

241

242

243

244

245

246

247

248

chemistry through deposition of feces sea lions affecting vegetation. This said, many parts of South Plaza Island remain inaccessible to sea lions and those areas still evidence the general differences observed in vegetation (reduced woody plant cover, lack of cactus) between North and South Plazas Islands.

Why land iguanas do not occur on North Plaza Island is not clear. The species' habitat is characterized as "dry areas with low growing shrubs and Opuntia cactus" (Kumar et al. 2020) which describes well North Plaza Island. Indeed, the abundance of cactus, woody plants and expanses of grasses on North Plaza Island suggests the habitat may be of high quality for land iguanas. Nesting habitat for land iguanas also is not likely limiting on North Plaza Island given the expanse of open soil present. We expect that land iguanas either never succeeded in colonizing this small offshore island (Hedrick 2019) despite being potentially able to do so, or that they did colonize it but went extinct historically.

\section{Conclusions}

Understanding how large-bodied herbivores engineer ecosystems is relevant today given widespread, current interest in reintroducing extant species back to places from which they were extirpated in historical times (Seddon, 2010; Johnson et al., 2018). With many proposed and in some cases ongoing trophic rewilding programs involving reptiles on islands premised upon the largely unevaluated assertion that restoring reptiles to islands will re-instate key ecological functions (Frazier, 2021), a better understanding of herbivore impacts on island ecosystems is required. An important outcome of this study is highlighting the importance of top-down effects of reptile herbivores and the potential of herbivore restoration to facilitate ecosystem recovery. We tested the hypothesis that plant communities are differently structured in the presence versus absence of land iguanas. We provide evidence that land iguanas substantially engineer the structure of plant communities. This study suggests that the widespread extinction of reptile herbivores, which once served as the dominant herbivore in many tropical oceanic ecosystems, may have profound implications for the status of these ecosystems, and the species that comprise them, today. Restoration of large-bodied reptilian herbivores, such as land iguanas and giant tortoises, should be regarded as an important component of restoration in ecosystems where they have been extirpated.

\section{Acknowledgements}

Support for the study was provided by the Galapagos Conservancy. We are grateful to Sean Burnett and Greg Carney for their efforts to secure and process the aerial imagery, to Sahila Kuldalkar for assistance in classifying the aerial imagery, and to the Galapagos National Park Directorate for permission and support to image the study sites. The manuscript was greatly improved thanks to the comments of three reviewers.

\section{References}

Ali R. 2004. The effect of introduced herbivores on vegetation in the Andaman Islands. Current Science 1103-1112.

Beatty CR, Cox NA, Kuzee ME. 2018. Biodiversity guidelines for forest landscape restoration opportunities assessments. Gland, Switzerland: IUCN.

Campbell K, Donlan CJ. 2005. Feral goat eradications on islands. Conservation Biology 19:1362-74.

Campbell KJ, Carrión V, Sevilla C. 2011. Increasing the scale of successful invasive rodent eradications in the Galapagos Islands. Galapagos Report. 2012:194-8.

PeerJ reviewing PDF | (2021:05:61822:2:0:NEW 23 Nov 2021) 
249 Christian KA, Tracy CR, Porter WP. 1984. Diet, digestion, and food preferences of Galapagos

250

251

252

253

254

255

256

257

258

259

260

261

262

263

264

265

266

267

268

269

270

271

272

273

274

275

276

277

278

279

280

281

282

283

284

285

286

287

288

289

290

291

292

293

294

295

296

297 land iguanas. Herpetologica 205-212.

Clapham, AR. 1936. Overdispersion in grassland communities and the use of statistical methods in plant ecology. J Ecol. 14:232-251.

Cooper Jr, WE, Vitt LJ. 2002. Distribution, extent, and evolution of plant consumption by lizards. Journal of Zoology 257:487-517.

Costantini D, Dell'Omo G, Casagrande S, Fabiani A, Carosi M, Bertacche V, Marquez C, Snell H, Snell H, Tapia W, Gentile G. 2005. Inter-population variation of carotenoids in Galápagos land iguanas (Conolophus subcristatus). Comparative Biochemistry and Physiology Part B: Biochemistry and Molecular Biology 142:239-44.

Debinski DM, Holt RD. 2000. A survey and overview of habitat fragmentation experiments. Conservation Biology 14:342-55.

Fabiani A, Trucchi E, Rosa S, Marquez C, Snell HL, Snell HM, Tapia Aguilera W, Gentile G. 2011. Conservation of Galápagos land iguanas: genetic monitoring and predictions of a long-term program on the island of Santa Cruz. Animal Conservation 14:419-429.

Falcón W, Hansen DM. 2018. Island rewilding with giant tortoises in an era of climate change. Philosophical Transactions of the Royal Society B: Biological Sciences. 373:20170442.

Fariña JM, Salazar S, Wallem KP, Witman JD, Ellis JC. 2003. Nutrient exchanges between marine and terrestrial ecosystems: the case of the Galapagos sea lion Zalophus wollebaecki. Journal of Animal Ecology 72:873-87.

Fondriest. 2014. In the Galapagos, scientists pioneer UAVs to count rare species and map habitat. Available at: https://www.fondriest.com/news/galapagos-scientists-pioneer-uavscount-rare-species-map-habitat.htm

Foufopoulos J, Ives AR. 1999. Reptile extinctions on land-bridge islands: life-history attributes and vulnerability to extinction. The American Naturalist 153:1-25.

Frazier J. 2021. The Galapagos: island home of giant tortoises. In: Gibbs JP, Cayot LJ, Tapia WA, eds. Galapagos Giant Tortoises. New York: Academic Press, 3-21.

Gibbons JW, Scott DE, Ryan TJ, Buhlmann KA, Tuberville TD, Metts BS, Greene JL, Mills T, Leiden Y, Poppy S, Winne CT. 2000. The Global Decline of Reptiles, Déjà Vu Amphibians. BioScience 50:653-66.

Grant BR, Grant, PR. 1981. Exploitation of Opuntia cactus by birds on the Galápagos. Oecologia 49:179-187.

Hansen DM, Donlan CJ, Griffiths CJ, Campbell KJ. 2010. Ecological history and latent conservation potential: large and giant tortoises as a model for taxon substitutions. Ecography 33:272-84.

Hedrick PW. 2019. Galapagos Islands endemic vertebrates: A population genetics perspective.

Heleno RH, Ross G, Everard AM, Memmott J, Ramos JA. 2011. The role of avian 'seed predators' as seed dispersers. Ibis 153:199-203.

ImageMagick Development Team. 2021. ImageMagick. Retrieved from https://imagemagick.org

Johnson CN, Prior LD, Archibald S, Poulos HM, Barton AM, Williamson GJ, Bowman DM. 2018. Can trophic rewilding reduce the impact of fire in a more flammable world? Philosophical Transactions of the Royal Society B: Biological Sciences 373:20170443.

Kumar K, Gentile G, Grant TD. 2020. Conolophus subcristatus. The IUCN Red List of Threatened Species 2020: e.T5240A3014082. https://dx.doi.org/10.2305/IUCN.UK.2020-2.RLTS.T5240A3014082.en. Downloaded on 12 August 2021.

Malhi Y, Doughty CE, Galetti M, Smith FA, Svenning JC, Terborgh JW. 2016. Megafauna and ecosystem function from the Pleistocene to the Anthropocene. Proceedings of the National Academy of Sciences 113:838-46.

Peer) reviewing PDF | (2021:05:61822:2:0:NEW 23 Nov 2021) 
298

299

300

301

302

303

304

305

306

307

308

309

310

311

312

313

314

315

316

317

318

319

320

321

322

323

324

325

326
Nogales M, González-Castro A, Rumeu B, Traveset A, Vargas P, Jaramillo P, Olesen JM, Heleno RH. 2017. Contribution by vertebrates to seed dispersal effectiveness in the Galápagos Islands: A community-wide approach. Ecology 98:2049-58.

Peck SB, Kukalová-Peck J. 1990. Origin and biogeography of the beetles (Coleoptera) of the Galápagos Archipelago, Ecuador. Canadian Journal of Zoology 68:1617-38.

Pérez-Méndez N, Jordano P, Valido A. 2018. Persisting in defaunated landscapes: reduced plant population connectivity after seed dispersal collapse. Journal of Ecology 106:93647.

R Core Team. 2017. R: A language and environment for statistical computing. R Foundation for Statistical Computing, Vienna, Austria. URL https://www.R-project.org/.

Seddon P. 2010. Species introductions. Restoration Ecology 18:796-802.

Shadish, W, Campbell DT, Cook, T.D.. 2002. Experimental and quasi-experimental designs for generalized causal inference. Boston, MA: Houghton Mifflin.

Simberloff D. 1976. Experimental zoogeography of islands: effects of island size. Ecology. 57:629-648.

Slavenko A, Tallowin OJ, Itescu Y, Raia P, Meiri S. 2016. Late Quaternary reptile extinctions: size matters, insularity dominates. Global Ecology and Biogeography 25:1308-20.

Snell HL, Christian KA. 1985. Energetics of Galápagos land iguanas: a comparison of two island populations. Herpetologica 41:437-42.

Snell HL, Snell HM, Stone P. 1994. Accelerated mortality of Opuntia on Isla Plaza Sur: another threat from an introduced vertebrate?. Noticias de Galápagos 53:19-20.

Traveset A, Nogales M, Vargas P, Rumeu B, Olesen JM, Jaramillo P, Heleno R. 2016. Galápagos land iguana (Conolophus subcristatus) as a seed disperser. Integrative Zoology 11:207-13.

Tzika AC, Rosa SF, Fabiani A, Snell HL, Snell HM, Marquez C, Tapia W, Rassmann K, Gentile G, Milinkovitch MC. 2008. Population genetics of Galápagos land iguana (genus Conolophus) remnant populations. Molecular Ecology 17:4943-52.

Valido A, Olesen JM. 2019. Frugivory and seed dispersal by lizards: a global review. Frontiers in Ecology and Evolution 5;7:49. 


\section{Figure 1}

The Plaza Islands in the Galapagos Archipelago, Ecuador where effects of land iguanas on terrestrial vegetation were assessed.

A) Geographic location of Plaza Islands, Galapagos, Ecuador, B) Galapagos land iguana (Conolophus subcristatus), South Plaza Island (image: A.Davey / Flickr, CC BY 2.0), C) The North and South Plaza Island study sites. North Plaza Island lacked land iguanas whereas South Plaza Island supported iguanas (at a density of $>50$ / hectare). Maps of each island depict plant associations mapped from ultra-high resolution ( $1 \mathrm{~cm}^{2}$ GSD) imagery obtained in 2012: woody plants (light blue), seasonal grasses (orange), succulents (light green), marine mammal impact areas (white), and inter-tidal zone (dark blue). Color of grid cell indicates the dominant vegetation type, i.e., that with the highest proportion. 


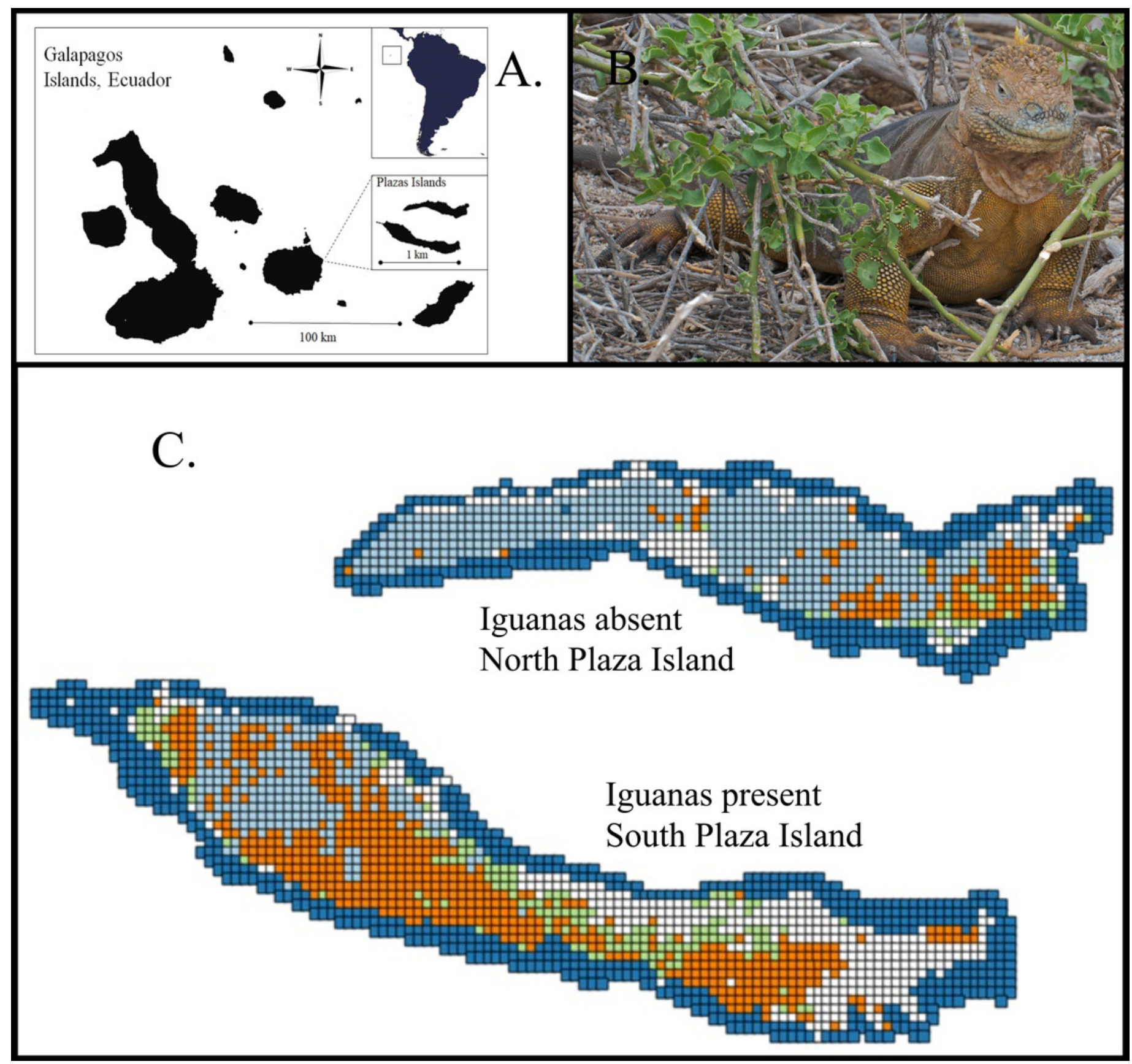




\section{Figure 2}

Contrasts between plant community parameters on two adjacent islands in the Galapagos, one with iguanas present and one with iguanas absent.

Contrasts between plant community parameters on two adjacent islands in the Galapagos, one with iguanas present and one with iguanas absent. All plots depict the probability densities of extent of different vegetation types on North Plaza Island (iguanas absent; 1,148, $5 \times 5 \mathrm{~m}$ grid cells) and South Plaza Island (iguanas present; 1,777 grid cells), except plot on lower right, which depicts woody cover extent in each $5 \times 5 \mathrm{~m}$ grid cell versus extent of woody vegetation in the eight neighboring grid cells on each island Intervals (LOESS smoothed and bounded by $95 \%$ confidence intervals). 

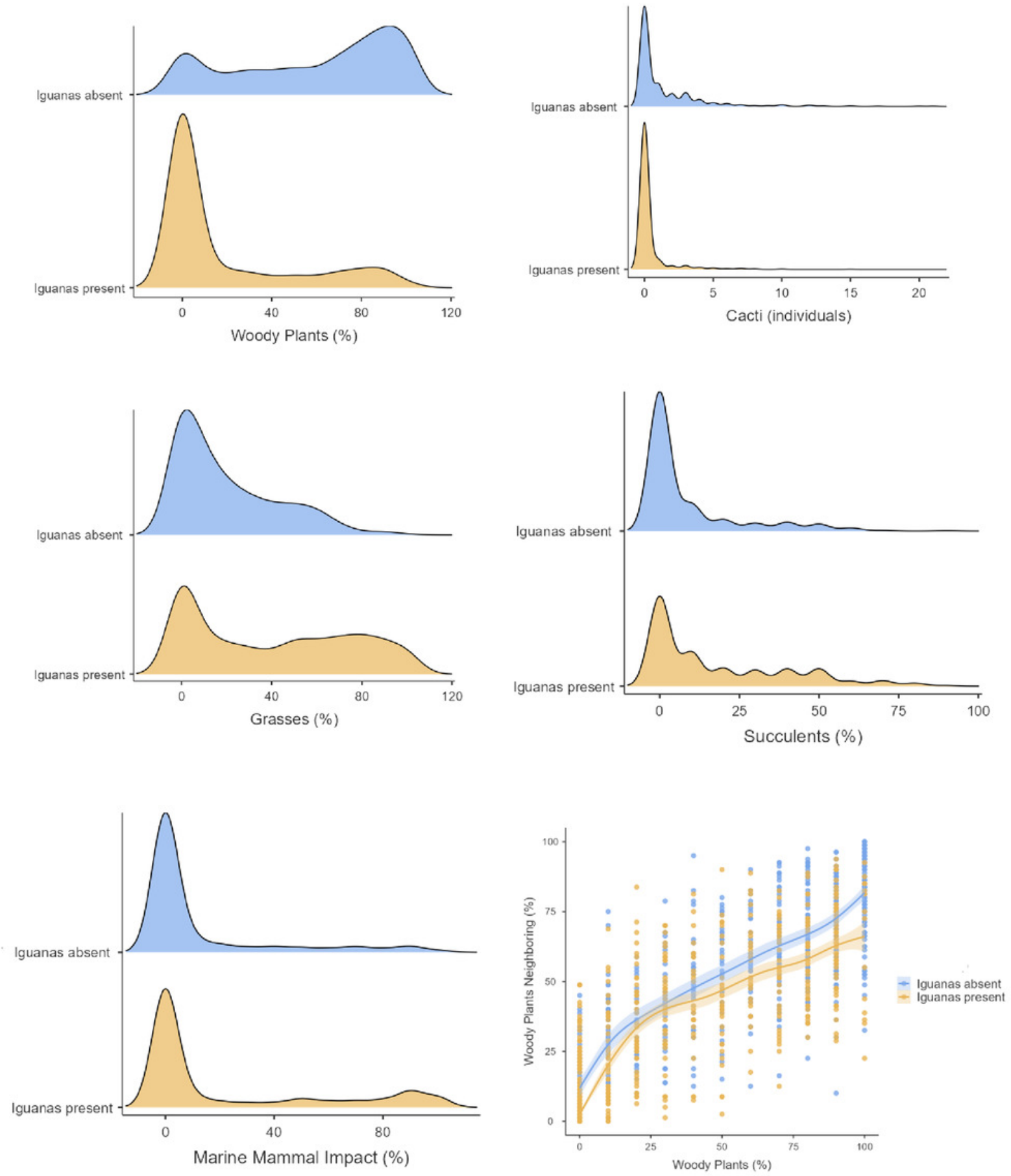


\section{Figure 3}

Nonmetric multidimensional scaling plot visualizing differences in plant community associations on two adjacent islands in the Galapagos Archipelago, one with land iguanas present and one with land iguanas absent.

Ordination based on Bray-Curtis dissimilarity index is split by island: iguanas present (South Plaza) and absent (North PLaza). The plot presents the kernel density estimation of the distribution of $1,148,5 \times 5 \mathrm{~m}$ grid cells on the island with iguanas absent and $1,7775 \times 5 \mathrm{~m}$ grid cells the island with iguanas present (derived from kde2d(); MASS package). To aid in interpretation, mean values for each univariate vegetation parameter comprising $>10 \%$ of the cells at a given peak are presented for each of the eight point clusters identified.

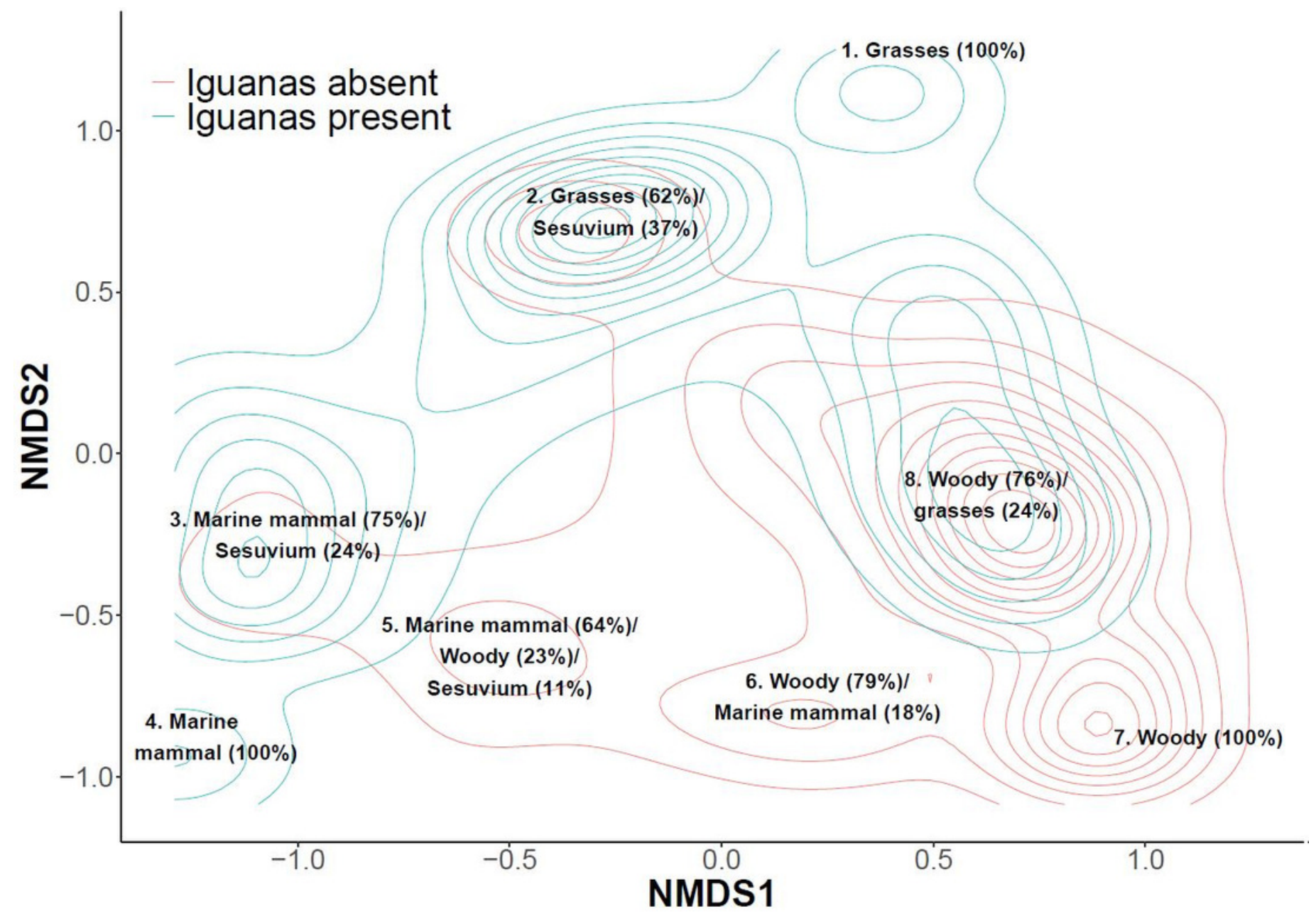

